\title{
Farklı Arazi Kullanımının Toprağın Bazı Mikrobiyal Oranları Üzerine Etkisi
}

\author{
İlyas BOLAT ${ }^{1 *}$, Ömer KARA ${ }^{2}$ \\ ${ }^{1}$ Bartın Üniversitesi, Orman Fakültesi, Orman Mühendisliği Bölümü, 74100, Bartın \\ ${ }^{2}$ Karadeniz Teknik Üniversitesi, Orman Fakültesi, Orman Mühendisliği Bölümü, 61080, Trabzon
}

\section{Öz}

Mikrobiyal biyokütle toprak oluşumunun canlı bileşeni olduğu için toprağın biyolojik durumu hakkında iyi bir gösterge olarak hizmet etmektedir. Bartın İli Ağdacı Köyü mevkiinde bulunan araştırma alanı; orman, mera ve tarım alanlarını içermektedir. Bu çalışmanın amacı; farklı arazi kullanım biçimi altındaki (orman, mera ve tarım) üst toprakların (0-5 cm) bazı mikrobiyal oranlarını $\left(\mathrm{C}_{\text {mic }} / \mathrm{C}_{\text {org }}, \mathrm{C}_{\text {mic }} / \mathrm{N}_{\text {mic }}\right.$ ve $\left.\mathrm{N}_{\text {mic }} / \mathrm{N}_{\text {total }}\right)$ belirlemektir. Çalışmanın materyal kısmını üst topraktan alınan toprak örnekleri oluşturmaktadır. Toprakların organik karbon ( $\mathrm{C}_{\text {org }}$ ), toplam azot $\left(\mathrm{N}_{\text {total }}\right)$, mikrobiyal biyokütle $\mathrm{C}\left(\mathrm{C}_{\text {mic }}\right)$ ve mikrobiyal biyokütle $\mathrm{N}\left(\mathrm{N}_{\text {mic }}\right)$ sonuçları elde edildikten sonra bu değerler birbirlerine oranlanarak toprakların mikrobiyal oranları $\left(\mathrm{C}_{\text {mic }} / \mathrm{C}_{\text {org }}, \mathrm{C}_{\text {mic }} / \mathrm{N}_{\text {mic }}\right.$ ve $\left.\mathrm{N}_{\text {mic }} / \mathrm{N}_{\text {total }}\right)$ elde edilmiştir. Çalışma sonucunda mikrobiyal oranlar $\left(\mathrm{C}_{\text {mic }} / \mathrm{C}_{\text {org }}, \mathrm{C}_{\text {mic }} / \mathrm{N}_{\text {mic }}\right.$ ve $\left.\mathrm{N}_{\text {mic }} / \mathrm{N}_{\text {total }}\right)$ bakımından orman, mera ve tarım alanları arasında farklılıkların olduğunu ortaya çıkarmıştır. Bu oranlar topraktaki organik maddenin ayrışma durumunu ve hakim mikroorganizma gruplarını (bakteri ve mantar) göstermesi bakımından önemlidir.

Anahtar Kelimeler: Orman, $\mathrm{C}_{\text {mic }} / \mathrm{C}_{\text {org }}(\%)$, era, $\mathrm{C}_{\text {mic }} / \mathrm{N}_{\text {mic }}$ oran1, Bartın.

\section{The Effect of Different Land Use on Some Microbial Ratios of Soil}

\begin{abstract}
Microbial biomass serves as a good indicator of the biological condition of the soil, because it is a living component of soil formation. The research area located in the Ağdacı Village of Bartın Province includes forest, pasture and agricultural areas. The aim of this study is to determine some microbial ratios $\left(\mathrm{C}_{\text {mic }} / \mathrm{C}_{\text {org }}, \mathrm{C}_{\text {mic }} / \mathrm{N}_{\text {mic }}\right.$ and $\left.\mathrm{N}_{\text {mic }} / \mathrm{N}_{\text {total }}\right)$ of the topsoil $(0-5 \mathrm{~cm})$ under different land use (forest, pasture and agriculture). The material part of the study comprises soil samples taken from the topsoil. After the organic carbon $\left(\mathrm{C}_{\text {org }}\right)$, total nitrogen $\left(\mathrm{N}_{\text {total }}\right)$, microbial biomass $\mathrm{C}\left(\mathrm{C}_{\text {mic }}\right)$ and microbial biomass $\mathrm{N}\left(\mathrm{N}_{\text {mic }}\right)$ results of the soils were obtained, these values were proportioned to each other, and then microbial ratios $\left(\mathrm{C}_{\text {mic }} / \mathrm{C}_{\text {org }}, \mathrm{C}_{\text {mic }} / \mathrm{N}_{\text {mic }}\right.$ and $\left.\mathrm{N}_{\text {mic }} / \mathrm{N}_{\text {total }}\right)$ were obtained. As a result of the study, it has been revealed that there are differences between forest, pasture and agricultural areas regarding microbial ratios $\left(\mathrm{C}_{\text {mic }} / \mathrm{C}_{\text {org }}, \mathrm{C}_{\text {mic }} / \mathrm{N}_{\text {mic }}\right.$ and $\left.\mathrm{N}_{\text {mic }} / \mathrm{N}_{\text {total }}\right)$. These ratios are of great importance in terms of demonstrating the decomposition status of organic matter in the soil, and the dominant microorganism groups (bacteria and fungi).
\end{abstract}

Keywords: Forest, $\mathrm{C}_{\text {mic }} / \mathrm{C}_{\text {org }}(\%)$, Pasture, $\mathrm{C}_{\text {mic }} / \mathrm{N}_{\text {mic }}$ ratio, Bartın.

\footnotetext{
*Sorumlu Yazar (Corresponding Author):

İlyas BOLAT (Doç. Dr.); Bartın Üniversitesi, Orman Fakültesi, Orman Mühendisliği 


\section{Giriş}

Büyük bir çoğunluğu bakteri ve mantarlardan meydana gelen fakat içinde aktinomiset, protozoa, alg ve virüslerin de bulunduğu toprak mikrobiyal biyokütlesi; karbon (C) depolaması, enerji akışı, ayrışma ve az da olsa gaz akışı gibi ekosistem süreçlerini düzenleyen çok önemli bir olgudur. Bu grup içerisinde bakteri ve mantarlar hem biyokütle hem de metabolik faaliyetler açısından en yaygın organizmalardır (Anderson ve Domsch, 1973; Parkinson ve Coleman, 1991; Cleveland vd., 2004). Mikrobiyal biyokütlenin ekosistem içindeki temel görevleri; organik maddelerin ayrışmasını sağlamak, organik ve inorganik maddelerden $\mathrm{N}, \mathrm{P}, \mathrm{K}, \mathrm{S}$ ve diğer iyonları mineralize etmek, besin elementlerini stoplazma içinde tutarak topraktan yıkanmasını önlemek, topraktaki zehirli maddeleri ayrıştırmak veya bünyelerinde biriktirmek, bitkilerin su ve besin elementi alımını artırmak, toprakların kırıntılı yapı kazanmasını sağlamak, humik maddeleri sentezlemek, zararlı toprak mikroorganizmaları ile mücadele etmek, antibiyotik üretmek, tohumların çimlenme engellerini kaldırmak, toprak oluşum ve gelişim olaylarına katılmak şeklinde özetlenebilir (Christensen, 1989).

Nielsen ve Winding, (2002) toprak mikrobiyal biyokütlesi, ayrışma oranları $\left(\mathrm{C}_{\text {mic }} / \mathrm{C}_{\text {org }}, \mathrm{C}_{\text {org }} / \mathrm{N}_{\text {total }}, \mathrm{N}_{\text {mic }} / \mathrm{P}_{\text {mic }}\right.$, $\mathrm{C}_{\text {mic }} / \mathrm{N}_{\text {mic }}$ v.b.) ve $\mathrm{N}$ mineralizasyonu arasında yakın bir ilişkinin olduğu ifade ederken, Carter vd., (1999) toprak mikrobiyal biyokütlesinin toprak organik karbonunun bir göstergesi olarak kullanılabileceğini ifade etmektedir. Anderson ve Domsch (1986)'a göre toprakların microbial biyokütle karbon $\left(\mathrm{C}_{\mathrm{mic}}\right)$ miktarı organik karbon $\left(\mathrm{C}_{\text {org }}\right)$ içeriği ile yakından ilişkilidir. Bu nedenle $\mathrm{C}_{\text {mic }} / \mathrm{C}_{\text {org }}$ oranı kullanılarak net $\mathrm{C}$ birikimi veya kaybı belirlenebilir. Genellikle, $\mathrm{C}_{\text {mic }} / \mathrm{N}_{\text {mic }}$ oranı mikrobiyal biyokütleyi oluşturan bakteriler (oranın 10-12 gibi yüksek olması), mantarlar (oranın 3-5 gibi düşük olması) ve aktinomisetler gibi canlı gruplarından hangisinin ortamda hakim olduğunu tahmin etmek amacıyla kullanılır. Kısaca mikrobiyal topluluğun yapısını ve durumunu ifade eder (Joergensen vd., 1995; García-Oliva vd., 2006; Yuan vd., 2007). $\mathrm{C}_{\mathrm{mic}} / \mathrm{C}_{\text {org }}$ yüzdesinde belirtildiği gibi, düşük

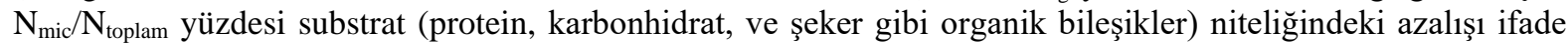
etmektedir (Bauhus vd., 1998). Bu çalışmanın amacı; farklı arazi kullanım biçimi altındaki (orman, mera ve tarım) üst toprakların $(0-5 \mathrm{~cm})$ bazı mikrobiyal oranlarını $\left(\mathrm{C}_{\text {mic }} / \mathrm{C}_{\text {org }}, \mathrm{C}_{\mathrm{mic}} / \mathrm{N}_{\text {mic }}\right.$ ve $\left.\mathrm{N}_{\text {mic }} / \mathrm{N}_{\text {total }}\right)$ elde etmek ve aralarındaki farklılıkları sorgulamaktır.

\section{Materyal ve Metot}

\subsection{Araştırma Alanlarının Yetişme Ortamı Özellikleri}

Bartın İli Ağdacı Köyü mevkiinde bulunan araştırma alanı; orman, mera ve tarım alanlarından oluşmaktadır. Çalışma alanının doğu ve güneydoğusunda Kurtlubey Mahallesi ile Kasapoğlu Mahallesi bulunurken, kuzeybatısında Oruç Mahallesi bulunmaktadır. Çalışma alanının içerisinde yer alan ve Bartın çayına akan en büyük dere türbe deresidir. Araştırma alanının güney batısında yer alan ve ortalama yükseltisi 200 metre olan Abdullah sırtı da çalışma alanına yakın en yüksek sırttır. Orman alanının ortalama yükseltisi 100 metre civarındadır. Arazinin baktığı yön kuzeydoğu ve ortalama eğimi \%55'tir. Orman alanı, meşcere tipleri haritasında 186 nolu bölmede yer almakta ve işletme ünitesi tipi olarak AA simgeleri ile gösterilen "Sosyal Baskılı Koruma Alanı" sınıfında yer almaktadır. Orman alanındaki kapalılık 0,9 ile 1 arasında değişmekte iken, bazı yerlerde sık ve sıkışık bir kapalılık da görülmektedir. Alan üzerinde yer alan ağaç türleri yapraklı türlerden oluşmaktadır ve ortalama olarak ağaç türlerinin yaşı 40 ile 55 arasında değişmektedir. Meşcerenin karışım şekli GnMKn (GürgenMeşe-Kayın)'dır. Meşcerenin altında aşırı bir diri örtü bulunmamakta, yaprak ve çürüntü tabakasına her yerde rastlanmamakta, buna karşılık 1-2 cm kalınlığında humus tabakası oluşumu yer almaktadır. Mera alanının ortalama yükseltisi 90 metredir. Ortalama eğimi \%40 civarında ve kuzey-kuzeydoğu bakıda yer almaktadır. Tarım alanın ortalama eğimi \%20'dir. Yükseltisi ortalama olarak 70 metredir, bakı olarak ise kuzey-kuzeybatı da yer almaktadır (Şekil 1). Araştırma alanındaki anakaya kalker (kireçtaşı) anakayasıdır. 


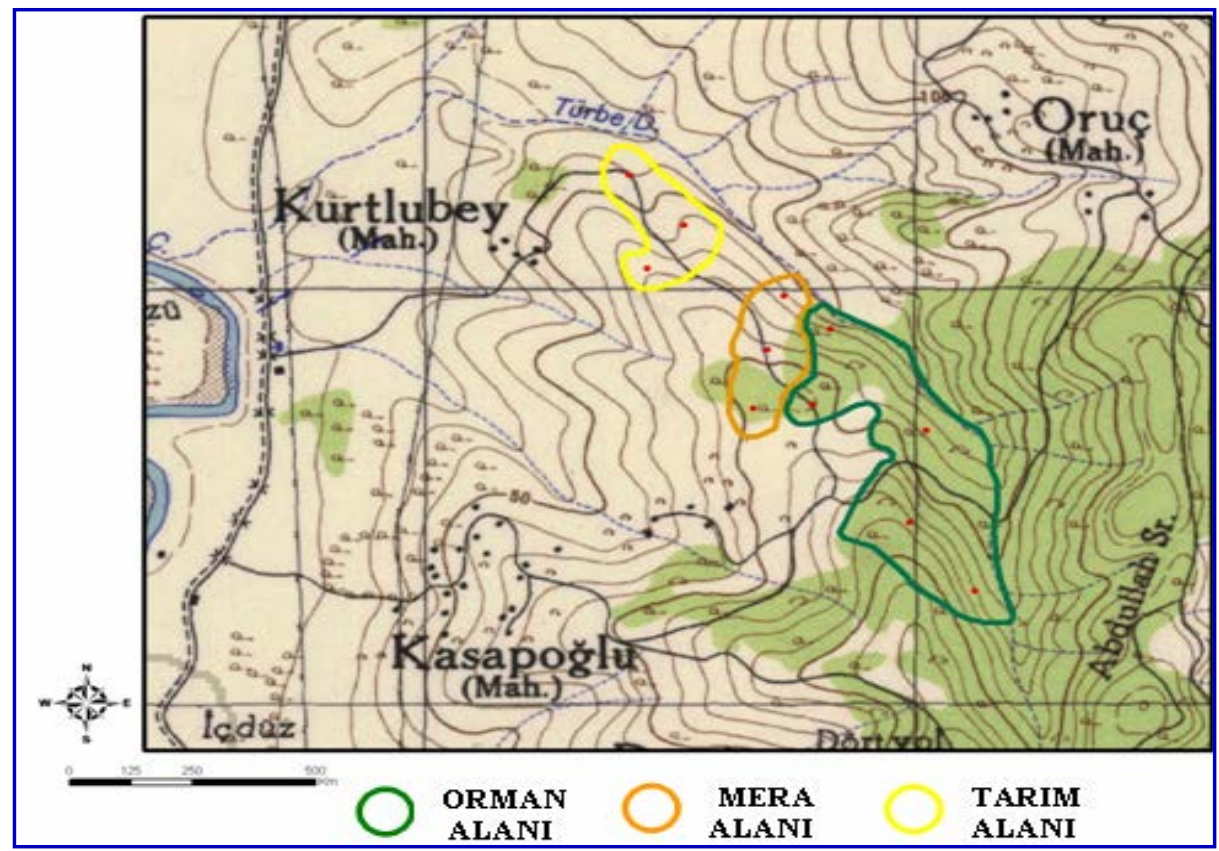

Şekil 1. Araştırma alanının 1/25 000 ölçekli harita (memleket haritası) üzerindeki yeri (HGK, 1984).

Bartın'ın iklim tipi Thornthwaite metoduna göre (Thornthwaite, 1948), nemli (B2), mezotermal (B1), yağış rejimine göre su açı̆̆ı yok veya pek az olan (r) ve deniz iklimi altında (b4') bulunan bir iklimdir. En az yağışlı aylar Mart ve Nisan aylarıdır. Yağışın en fazla düştüğü ay Ekim ayıdır (123.8). Oldukça nemli bir iklime sahip Bartın'da nisbi (bağıl) nem \%80 civarındadır. Orman alanında yayılış gösteren bitki örtüsü: Doğu kayını (Fagus orientalis Lipsky), Sapsız meşe (Quercus petraea (Mattuschka) Liebl.) Adi gürgen (Carpinus betulus L.) ve yer yer de olsa Gümüşi ıhlamur (Tilia tomentosa Moench.) gibi yapraklı orman ağaçlarından oluşurken, Mor çiçekli orman gülü (Rhododendron ponticum L. subsp. ponticum), Karadeniz defnesi (Daphne pontica L.), Çoban püskülü (Ilex colchica Poj.), Alıç (Crataegus curvisepala Lindman) ve Tavşan memesi (Ruscus aculeatus L.) gibi çalılardan oluşmaktadır. Mera alanında yayılış gösteren bitki örtüsü: Domuz ayrı̆̆ı (Dactylis glomerata L.), Beyaz çiçekli papatya (Bellis perennis L.), Sütleğen (Euphorbia sp.), Turnagagası (Geranium sp.), Adi fiğ (Vicia sativa L.), Üçgül (Trifolium sp.), Kartal eğreltisi (Pteridium aquilinum L.) ve Böğürtlen (Rubus sp.) gibi otsu türlerden oluşurken, alan üzerinde çalı olarak Kuşburnu (Rosa canina L.) da bulunmaktadır. Tarım alanında yayılış gösteren bitki örtüsü: Tarım alanında dönüşümlü olarak Mısır (Zea mays L.) ve Buğday (Triticum vulgare L.) tarımı yapılmaktadır. Hasat dönemlerinin sonunda ise otsu bitki olarak alan üzerinde Adi fiğ (Vicia sativa L.) bulunmaktadır.

\subsection{Materyal}

Çalışmanın materyal kısmını üst topraktan $(0-5 \mathrm{~cm})$ alınan toprak örnekleri oluşturmaktadır. Mikrobiyal biyokütle $\mathrm{C}\left(\mathrm{C}_{\text {mic }}\right)$ ve $\mathrm{N}\left(\mathrm{N}_{\text {mic }}\right)$ analizleri için orman, mera ve tarım alanlarından vejetasyon dönemi içerisinde Ağustos 2006'da her alandan 15'er adet toprak örneği alınmıştır. Toprak örneklerinin alınacağ yerlerin herhangi bir etkiye uğramamış, doğal durumunu koruyan yerlerden olmasına özen gösterilmiştir. Ayrıca toprakların organik C $\left(\mathrm{C}_{\text {org }}\right)$ ve toplam N ( $\left.\mathrm{N}_{\text {total }}\right)$ özelliklerini belirlemek için her örnek alandan hacim örnekleri de alınmıştır.

\subsection{Metot}

Toprakların organik $\mathrm{C}$ ve toplam $\mathrm{N}$ içeriklerinin belirlenmesi için toprak örnekleri hava kurusu hale gelene kadar kurutulmuşlardır. Toprak örnekleri taş ve kökleri ayrılarak porselen havanlarda öğütülmüştür. Daha sonra ise öğütülen toprak örnekleri 2 mm'lik eleklerden geçirilmiştir. Yapılan bütün analizler iki tekrarlı olacak şekilde gerçekleştirilmiştir. Toprak örneklerinin organik karbon miktarı, 0,25 mm'lik elekten geçirilmiş $0,5 \mathrm{~g}$ toprak kullanılarak Wackley-Black ıslak yakma yöntemi ile bulunmuştur (Irmak, 1954; Gülçur, 1974). Toplam azot modifiye Kjeldahl yöntemine göre bulunmuştur. Modifiye edilmiş Kjeldahl yöntemi; toprakta organik formda bulunan azot ile amonyum formunda bulunan anorganik azotu, genellikle sülfürik asit $\left(\mathrm{H}_{2} \mathrm{SO}_{4}\right)$ ile yaş yakmak sureti ile amonyuma $\left(\mathrm{NH}_{4}\right)$ çevirmek ve bu amonyumu alkali ortamda amonyak $\left(\mathrm{NH}_{3}\right)$ halinde uçurup, hafif asit ortamda bağlamak ve bunu titrasyon yolu ile hesaplamak esasına dayanır (Kacar, 1996). 
Toprak örneklerinin mikrobiyal biyokütle C içerikleri kloroform-fumigasyon-ekstraksiyon yöntemine göre belirlenmiştir (Brookes vd., 1985; Vance vd., 1987a). Mikrobiyal biyokütle karbon (C $\mathrm{mic}_{\text {) }}$ içeriği Eşitlik 1 kullanılarak hesap edilmiştir.

$\mathrm{C}_{\text {mic }}=\mathrm{Ec}^{*} k C$

Eşitlikteki Ec= Fumigasyonlu ve fumigasyonsuz toprak örneğinin mikrobiyal biyokütle $\mathrm{C}$ içeriği arasındaki farkı ( $\mathrm{C}_{\text {fumigasyonlu}}-\mathrm{C}_{\text {fumigasyonsuz }}$ ), $k C=2,64$ (fumigasyondan sonra ekstrakt edilebilen biyokütle $\mathrm{C}$ kısmı) katsayısını ifade etmektedir (Vance vd., 1987a).

Örneklerin mikrobiyal biyokütle N içeriği Kjeldahl digestion-destilasyon-titrasyon metoduna göre belirlenmiş ve Eşitlik 2'ye göre de hesaplanmıştır (Brookes vd., 1985; Anderson ve Ingram, 1996).

$\mathrm{N}_{\text {mic }}=\mathrm{F}_{\mathrm{N}} / \mathrm{kN}$

Eşitlikteki $\mathrm{F}_{\mathrm{N}}=$ Fumigasyonlu ve fumigasyonsuz toprak örneğinin mikrobiyal biyokütle $\mathrm{N}$ içeriği arasındaki fark ( $\mathrm{N}_{\text {fumigasyonlu}}-\mathrm{N}_{\text {fumigasyonsuz }}$ ), $\mathrm{kN}=$ Mineralize olabilen mikrobiyal biyokütle azotunun katsayısı'dır $(0,54)$.

Toprakların organik C ( $\left.\mathrm{C}_{\text {org }}\right)$, toplam $\mathrm{N}\left(\mathrm{N}_{\text {total }}\right)$, mikrobiyal biyokütle $\mathrm{C}\left(\mathrm{C}_{\mathrm{mic}}\right)$ ve $\mathrm{N}\left(\mathrm{N}_{\text {mic }}\right)$ sonuçları elde edildikten sonra (Kara ve Bolat, 2008a, b) bu değerler birbirlerine oranlanarak toprakların mikrobiyal oranları $\left(\mathrm{C}_{\mathrm{mic}} / \mathrm{C}_{\mathrm{org}}\right.$, $\mathrm{C}_{\text {mic }} / \mathrm{N}_{\text {mic }}$ ve $\mathrm{N}_{\text {mic }} / \mathrm{N}_{\text {total }}$ ) elde edilmiştir.

\subsection{Verilerin Değerlendirilmesi}

Elde edilen verilerin değerlendirilmesinde SPSS 16.0 paket programı kullanılmıştır. Arazi kullanım biçimlerine göre toprakların mikrobiyal oranları bakımından fark olup olmadığını belirlemek için tek yönlü varyans analizi (One-way ANOVA) yapılmıştır. Varyans analizi sonucunda aralarında fark çıkan $(\mathrm{P}<0,05)$ arazi kullanım biçimlerinden farklı olanların belirlemesi amacıyla S-N-K (Student-Newman-Keuls) testi uygulanmıştır (Özdamar, 1999; Altunışık vd., 2002).

\section{Bulgular ve Tartışma}

\subsection{Orman, Mera ve Tarım Topraklarındaki $C_{m i c} / C_{o r g}(\%)$ Oranları}

Topraklara ait ortalama $\mathrm{C}_{\text {mic }} / \mathrm{C}_{\text {org }}$ oranları orman alanında 2,48, mera alanında 3,33 ve tarım alanında 4,07 bulunmuştur. Varyans analizi sonucuna göre farklı arazi kullanım biçimleri $\mathrm{C}_{\mathrm{mic}} / \mathrm{C}_{\text {org }}$ oranlarında istatistiksel olarak önemli farklara $(\mathrm{P}<0,05)$ yol açmıştır (Tablo 1).

Tablo 1. Farklı arazi kullanım alanlarındaki toprakların $\mathrm{C}_{\mathrm{mic}} / \mathrm{C}_{\text {org }}$ oranına ilişkin varyans analizi sonuçları.

\begin{tabular}{lllllll}
\hline Ayrışma Oranı & $\begin{array}{l}\text { Varyasyon } \\
\text { Kaynağı }\end{array}$ & $\begin{array}{l}\text { Kareler } \\
\text { Toplamı }\end{array}$ & $\begin{array}{l}\text { Serbestlik } \\
\text { Derecesi }\end{array}$ & $\begin{array}{l}\text { Kareler } \\
\text { Ortalaması }\end{array}$ & $\begin{array}{l}\text { F } \\
\text { Değeri }\end{array}$ & $\begin{array}{l}\text { Önem } \\
\text { Düzeyi (P) }\end{array}$ \\
\cline { 2 - 6 } Cmic $_{\text {Corg }}$ (\%) & Gruplar Arası & 38,134 & 2 & 19,067 & 33,167 & $0,000^{*}$ \\
& Gruplar İçi & 50,014 & 87 & 0,575 & & \\
& Toplam & 88,148 & 89 & & \\
\hline
\end{tabular}

${ }^{*}: 0,05$ önem düzeyi ile anlamlı.

Orman, mera ve tarım alanlarından farklı olanları belirlemek amacıyla S-N-K testi uygulanmış ve bu testin sonucuna göre ise orman, mera ve tarım alanlarının $\mathrm{C}_{\mathrm{mic}} / \mathrm{C}_{\text {org }}$ ayrışma oranı bakımından birbirinden farklı gruplarda yer aldığı ortaya çıkmıştır (Şekil 2). 


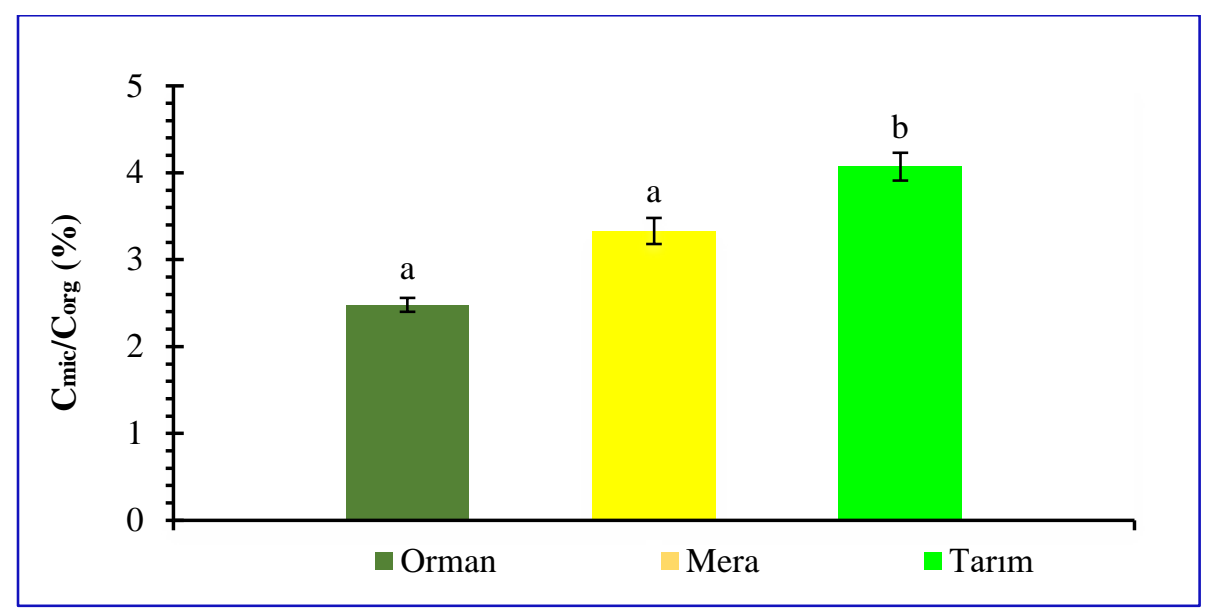

Şekil 2. $\mathrm{C}_{\text {mic }} / \mathrm{C}_{\text {org }}$ oranının farklı arazi kullanım biçimine göre değişimi. Sütunlar ortalama \pm standart hatayı ifade etmektedir. Farklı harfler $\mathrm{P}<0,05$ önem düzeyinde ortalamalar arasında fark olduğunu göstermektedir.

$\mathrm{C}_{\text {mic }} / \mathrm{C}_{\text {org }}$ oranı orman alanında en düşük $(\% 2,48)$ tarım alanında en yüksek $(\% 4,07)$ bulunmuştur. Orman topraklarındaki düşük $\mathrm{C}_{\mathrm{mic}} / \mathrm{C}_{\text {org }}$ oranı toprak canlıları tarafından substrat alınabilirliğinin nispeten düşük olduğunu göstermektedir. Bu durum ise toprak organik maddesinin sadece çok az bir kısmının toprak canlıları tarafından metabolize edildiğini ifade etmektedir. Nitekim Bauhus vd. (1998)'de $\mathrm{C}_{\mathrm{mic}} / \mathrm{C}_{\text {org }}$ oranındaki azalışın substrat niteliğindeki bir azalışı ifade ettiğini vurgulamaktadır. Hu vd. (1997)'de yaptıkları çalışmada benzer yönde sonuçlar elde etmiştir; orman alanında düşük $\mathrm{C}_{\mathrm{mic}} / \mathrm{C}_{\text {org }}$ oranı tarım alanında ise ormana nazaran yüksek $\mathrm{C}_{\mathrm{mic}} / \mathrm{C}_{\text {org }}$ oranı elde etmiştir. Çalışmada ayrıca farklı arazi kullanım biçimlerinin $\mathrm{C}_{\mathrm{mic}} / \mathrm{C}_{\text {org }}$ oranını önemli bir şekilde etkilediği de ifade edilmektedir.

Bu çalışmada elde edilen sonuçlar Luizao vd. (1992) tarafından yapılan çalışmada tropikal orman toprakları için bulunan oranlara (\%1,5-5,3) yakın hatta belirtilen aralık içerisinde buna karşılık Vance vd. (1987b) tarafından ılıman orman toprakları için bulunan oranlardan $(\% 1,8-2,9)$ yüksektir. Ayrıca Cmic/Corg oranının Jenkinson (1988) \%1-3 arasında, Kaiser vd. (1992) ve Franzluebbers vd. (1999) \%0,1-10 arasında değişebileceğini ifade etmektedirler. Anderson ve Domsch (1989) Cmic/Corg oranındaki bu geniş aralığın ve değişkenliğin sebebinin toprak özellikleri, vejetasyon örtüsü, arazi kullanım biçimi ve bunlara ilave olarak örnekleme zamanı ve kullanılan metod olabileceğini belirtmektedirler. Yapılan bir çalışmada farklı meşcere yaşı, toprak tipi ve ağaç türleri altındaki toprakların Cmic/Corg oranının \%0,8 ile 1,9 arasında değiştiği ifade edilmektedir (Bauhus vd., 1998).

\subsection{Orman, Mera ve Tarım Topraklarındaki $C_{m i c} / N_{m i c}$ Oranları}

Cmic/Nmic oranları orman alanında 2,87 ile 19,60 arasında (ortalama 9,01 \pm 0,71), mera alanında 5,46 ile 20,23 arasında (ortalama 9,97 \pm 0,61), tarım alanında, 4,93 ile 30,49 arasında (ortalama 12,80 \pm 1,09) değişmektedir. Yapılan varyans analizi sonucuna göre; orman, mera ve tarım alanları arasında Cmic/Nmic oranı bakımdan farklılık $(\mathrm{P}<0,05)$ ortaya çıkmıştır (Tablo 2).

Tablo 2. Farklı arazi kullanım alanlarındaki toprakların $\mathrm{C}_{\mathrm{mic}} / \mathrm{N}_{\text {mic }}$ oranına ilişkin varyans analizi sonuçları.

\begin{tabular}{lllllll}
\hline Ayrışma Oranı & $\begin{array}{l}\text { Varyasyon } \\
\text { Kaynağı }\end{array}$ & $\begin{array}{l}\text { Kareler } \\
\text { Toplamı }\end{array}$ & $\begin{array}{l}\text { Serbestlik } \\
\text { Derecesi }\end{array}$ & $\begin{array}{l}\text { Kareler } \\
\text { Ortalaması }\end{array}$ & F Değeri & $\begin{array}{l}\text { Önem } \\
\text { Düzeyi (P) }\end{array}$ \\
\cline { 2 - 7 } $\mathbf{C}_{\text {mic }} / \mathbf{N}_{\text {mic }}$ & Gruplar Arası & 232,273 & 2 & 116,137 & 5,532 & $0,005^{*}$ \\
& Gruplar İçi & 1826,333 & 87 & 20,992 & & \\
& Toplam & 2058,606 & 89 & & \\
\hline
\end{tabular}

* $: 0,05$ önem düzeyi ile anlaml.

S-N-K testi uygulanarak orman, mera ve tarım alanları karşılaştırıldığında, $\mathrm{C}_{\text {mic }} / \mathrm{N}_{\text {mic }}$ oranları orman ve mera alanına ait topraklarda farklı olmadığı, ancak tarım alanına ait toprakların $\mathrm{C}_{\text {mic }} / \mathrm{N}_{\text {mic }}$ oranının bu iki arazi kullanım biçimine göre daha yüksek olduğu bulunmuştur (Şekil 3). 


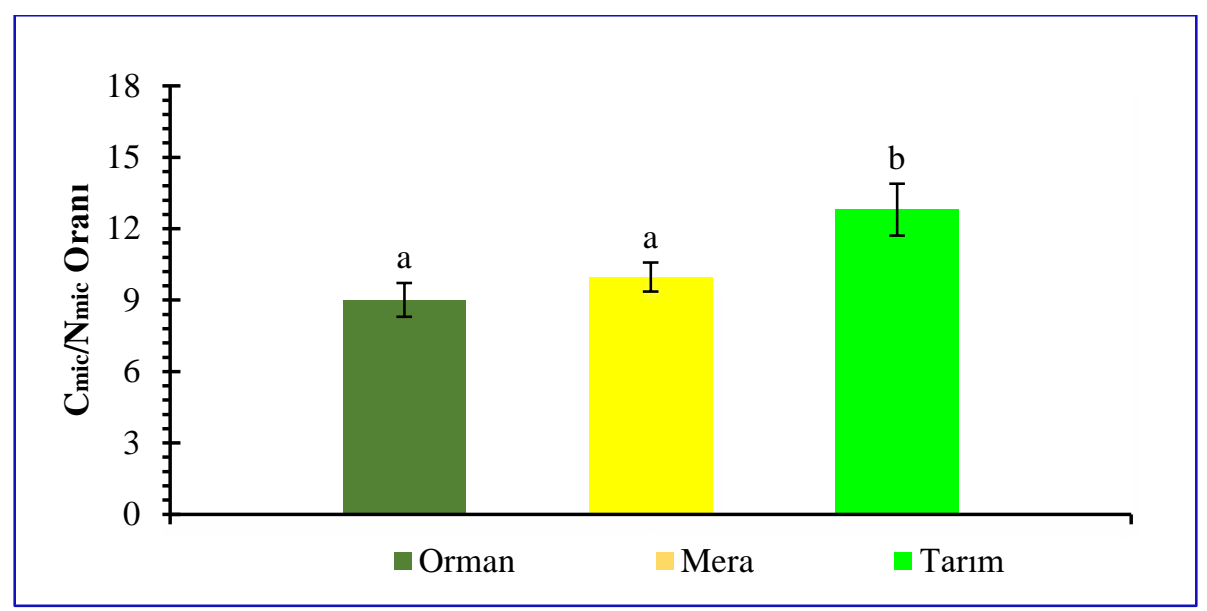

Şekil 3. $\mathrm{C}_{\text {mic }} / \mathrm{N}_{\text {mic }}$ oranının farklı arazi kullanım biçimine göre değişimi. Sütunlar ortalama \pm standart hatayı ifade etmektedir. Farklı harfler $\mathrm{P}<0,05$ önem düzeyinde ortalamalar arasında fark olduğunu göstermektedir.

Genel olarak $\mathrm{C}_{\text {mic }} / \mathrm{N}_{\text {mic }}$ oranının yüksek olması (10-12) mantarların, düşük çıkması (3-5) bakterilerin ortamda hakim olduğuna işaret etmektedir (Jenkinson ve Ladd, 1981). Yapılan çalışmada, tarım topraklarında yüksek $\mathrm{C}_{\text {mic }} / \mathrm{N}_{\text {mic }}$ oranı mantar faaliyetinin yüksek olduğunu, orman topraklarında ise düşük $\mathrm{C}_{\text {mic }} / \mathrm{N}_{\text {mic }}$ oranı bakteri faaliyetinin yüksek olduğunu göstermektedir. Elde edilen bu sonuç çalışmanın yapıldığı toprakların mikrobiyal strüktürünün birbirinden farklı olduğunu da ifade etmektedir.

Ayrıca toprağın fiziksel ve kimyasal özellikleri toprakta bulunan mikroorganizmaları etkilediği için $C_{\text {mic }} / N_{\text {mic }}$ oranı üzerinde de etkili olabilmektedir. Nitekim Tate vd. (1988)' de yaptıkları çalışmada $\mathrm{C}_{\text {mic }} / \mathrm{N}_{\text {mic }}$ oranının toprak mikroorganizma taksonlarına göre farklı olabileceğini ve toprakta bulunan mikrobiyal populasyonun da toprak tiplerine göre değişebileceğini ifade etmektedirler. García-Oliva vd. (2006) yaptıkları çalışmada orman alanında $\mathrm{C}_{\text {mic }} / \mathrm{N}_{\text {mic }}$ oranını $9( \pm 1)$, mera alanında $18( \pm 4)$ olarak bulmuşlar ve aralarında istatistiki olarak fark olduğunu ifade etmişlerdir. Yapılan diğer bir çalışmada üst topraktaki $\mathrm{C}_{\text {mic }} / \mathrm{N}_{\text {mic }}$ oranı ortalama olarak, mera alanında 2,8, yanmış mera alanında 5,1, Pinus radiata ormanında 4,8 ve orman içi açıklıkta 4,7 olarak bulunmuştur. Ayrıca mikrobiyal biyokütle havuzunun vejetasyon tipinden önemli bir şekilde etkilendiği de ifade edilmektedir (Yeates ve Saggar,1998). Jörgensen (1995) $\mathrm{C}_{\text {mic }} / \mathrm{N}_{\text {mic }}$ oranını tarım topraklarında 3,4, orman topraklarında ise 20,8 olarak bulmuştur ve 81 toprağın ortalaması olarak ise $\mathrm{C}_{\text {mic }} / \mathrm{N}_{\text {mic }}$ oranını 6,1 olarak tespit etmiştir. Joergensen vd. (1995)'de yaptıkları çalışmada kayın ormanları için $\mathrm{C}_{\text {mic }} / \mathrm{N}_{\text {mic }}$ oranının 5,4-17,3 arasında değiştiğini belirtmektedirler. Bir başka çalışmada farklı meşcere yaşı, toprak tipi ve ağaç türleri altındaki toprakların $\mathrm{C}_{\text {mic }} / \mathrm{N}_{\text {mic }}$ oranının 5,2 ile 12,9 arasında değiştiği belirtilmiştir (Bauhus vd., 1998).

\subsection{Orman, Mera ve Tarım Topraklarındaki $N_{\text {mic }} / N_{\text {total }}$ Oranları}

Farklı arazi kullanımı altındaki toprakların $\mathrm{N}_{\text {mic }} / \mathrm{N}_{\text {total }}$ oranları; orman alanında $\% 1,91$ ile 7,18 arasında (ortalama $\% 4,06 \pm 0,25$ ), mera alanında \%1,46 ile 8,75 arasında (ortalama \%3,73 \pm 0,31), tarım alanında \%1,20 ile 5,65 arasında (ortalama \%2,84 $\pm 0,17$ ) değişim gösterdiği bulunmuştur. Varyans analizi sonucuna göre; $\mathrm{N}_{\text {mic }} / \mathrm{N}_{\text {total }}$ oranları arazi kullanım biçimine göre istatistiki olarak anlamlı $(\mathrm{P}<0,05)$ bir fark göstermektedir (Tablo 3).

Tablo 3. Farklı arazi kullanım alanlarındaki toprakların $\mathrm{N}_{\text {mic }} / \mathrm{N}_{\text {total }}$ oranına ilişkin varyans analizi sonuçları.

\begin{tabular}{lllllll}
\hline $\begin{array}{l}\text { Ayrışma } \\
\text { Oranı }\end{array}$ & $\begin{array}{l}\text { Varyasyon } \\
\text { Kaynağı }\end{array}$ & $\begin{array}{l}\text { Kareler } \\
\text { Toplamı }\end{array}$ & $\begin{array}{l}\text { Serbestlik } \\
\text { Derecesi }\end{array}$ & $\begin{array}{l}\text { Kareler } \\
\text { Ortalaması }\end{array}$ & F Değeri & $\begin{array}{l}\text { Önem } \\
\text { Düzeyi (P) }\end{array}$ \\
\cline { 2 - 7 } $\begin{array}{l}\mathbf{N}_{\text {mic }} / \mathbf{N}_{\text {total }} \\
\mathbf{( \% )}\end{array}$ & Gruplar Arası & 23,999 & 2 & 12,000 & 6,210 & $0,003^{*}$ \\
& Gruplar İçi & 168,117 & 87 & 1,932 & & \\
& Toplam & 192,116 & 89 & & & \\
& & & & & & \\
\hline
\end{tabular}

${ }^{*}: 0,05$ önem düzeyi ile anlamlı.

Orman, mera ve tarım alanları arasındaki farkı belirlemek amacıyla S-N-K testi uygulanmıştır. Bu testin sonucuna göre; $\mathrm{N}_{\text {mic }} / \mathrm{N}_{\text {total }}$ oranları orman ve mera alanına ait topraklarda aynı, tarım alanına ait topraklarda ise bu iki arazi 
kullanım biçimine göre daha düşük olduğu görülmüştür (Şekil 4).

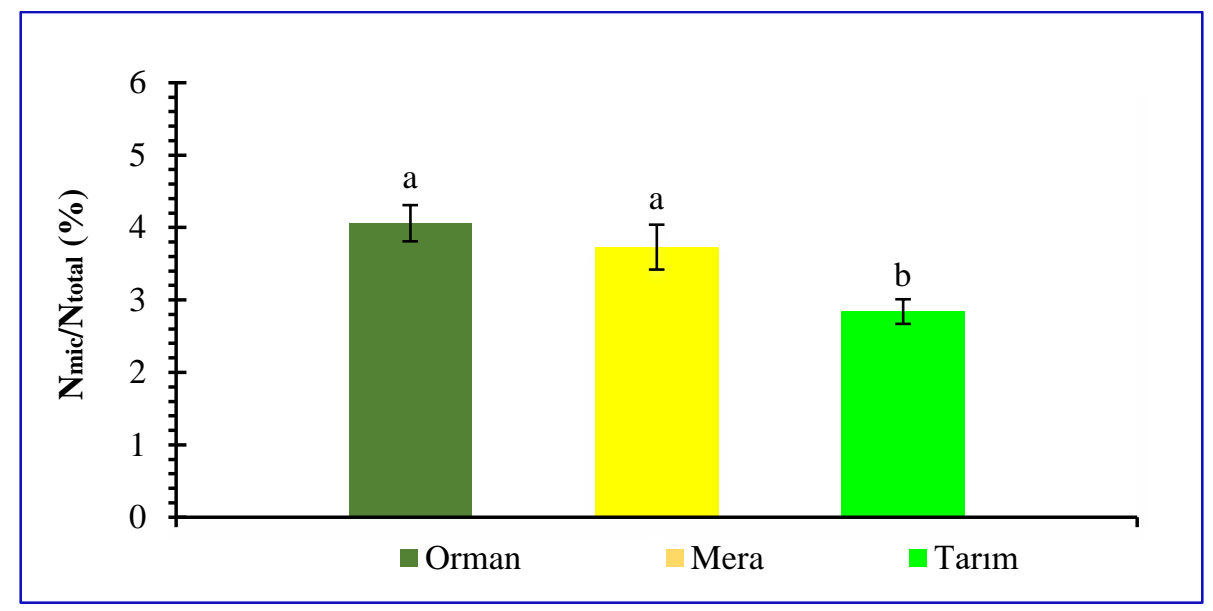

Şekil 4. $\mathrm{N}_{\text {mic }} / \mathrm{N}_{\text {total }}$ oranının farklı arazi kullanım biçimine göre değiş̧imi. Sütunlar ortalama \pm standart hatayı ifade etmektedir. Farklı harfler $\mathrm{P}<0,05$ önem düzeyinde ortalamalar arasında fark olduğunu göstermektedir.

Çalışma sonucunda elde edilen $\mathrm{N}_{\text {mic }} / \mathrm{N}_{\text {total }}$ oranı Priha ve Smolander (1997) tarafından 1lıman kuşak ormanları için belirlenen (\%2,0-8,0) aralığının içerisinde yer almaktadır. $\mathrm{N}_{\text {mic }} / \mathrm{N}_{\text {total }}$ oranının orman alanında, mera ve tarım alanından yüksek çıkması makro ve mikroflora yönünden orman alanın daha zengin olmasından kaynaklanabilir. Khan ve Joergensen (2006) yaptıkları çalışmada nispeten yüksek $\mathrm{N}_{\text {mic }} / \mathrm{N}_{\text {total }}$ yüzdesinin alınabilir azot bileşiklerinin genellikle sınırlandırılmadığını vurgulamaktadır. Ayrıca yüksek $\mathrm{N}_{\text {mic }} / \mathrm{N}_{\text {total }}$ değerleri mikroorganizmalar tarafından bütün organik kaynakların iyi bir şekilde alınabildiğini, bitki artıklarının düzenli bir şekilde ayrıştırılarak toprağa karıştığını ve düşük toprak organik madde miktarını da yansıtmaktadır. Bauhus vd. (1998)'e göre $\mathrm{C}_{\text {mic }} / \mathrm{C}_{\text {org }}$ oranında olduğu gibi $\mathrm{N}_{\text {mic }} / \mathrm{N}_{\text {total }}$ oranındaki azalış substrat niteliğindeki bir azalışı ifade etmektedir. Bununla birlikte $\mathrm{N}_{\text {mic }} / \mathrm{N}_{\text {total }}$ oranındaki aşırı bir atış ise azot eksikliğini belirtmektedir. Bu durumda; toprak azotunun büyük bir kısmının toprak canlıları tarafından fikse edilmiş olabileceği çalışmada vurgulanmaktadır. Ayrıca çalışmada farklı meşcere yaşı, toprak tipi ve ağaç türleri altındaki toprakların $\mathrm{N}_{\text {mic }} / \mathrm{N}_{\text {total }}$ oranının \%2,3 ile 6,0 arasında değiştiği ifade edilmektedir. Yapılan diğer bir çalışmada, $\mathrm{N}_{\text {mic }} / \mathrm{N}_{\text {total }}$ oranı kayın ormanında \%2,41, iğne yapraklı orman alanında \%2,17 olarak bulunmuş ve aralarında istatistiki olarak fark olduğu belirtilmiştir (Zhong ve Makeschin, 2006).

\section{Sonuç ve Öneriler}

Topraklara ait ortalama $\mathrm{C}_{\text {mic }} / \mathrm{C}_{\text {org }}$ oranı en düşük orman alanında, sonra mera alanında ve en yüksek tarım alanında bulunmuştur. Benzer şekilde $\mathrm{C}_{\text {mic }} / \mathrm{N}_{\text {mic }}$ oranı en düşük orman alanında, en yüksek tarım alanında bulunmuştur. Ayrıca orman ve mera topraklarına ait oranların birbirine benzerlik gösterdiği tespit edilmiştir. Farklı arazi kullanımı altındaki toprakların $\mathrm{N}_{\text {mic }} / \mathrm{N}_{\text {total }}$ oranı en yüksek orman alanında, en düşük tarım alanında bulunmuştur. Ayrıca orman ve mera topraklarına ait $\mathrm{N}_{\text {mic }} / \mathrm{N}_{\text {total }}$ oran değerleri birbirine benzerlik gösterdiği saptanmıştır. Yapılan çalışma mikrobiyal biyokütle $\mathrm{C}$, mikrobiyal biyokütle $\mathrm{N}$ değerleri ve mikrobiyal oranlar $\left(\mathrm{C}_{\mathrm{mic}} / \mathrm{C}_{\text {org }}\right.$, $\mathrm{C}_{\text {mic }} / \mathrm{N}_{\text {mic }}$ ve $\mathrm{N}_{\text {mic }} / \mathrm{N}_{\text {total }}$ ) bakımından orman, mera ve tarım alanları arasında farklılıkların olduğunu ortaya çıkarmıştır.

$\mathrm{Bu}$ oranlar topraktaki organik maddenin ayrışma durumunu ve hakim mikroorganizma gruplarını (bakteri ve mantar) göstermesi bakımından önemlidir. Yukarıda ifade edildiği gibi $\mathrm{C}_{\text {mic }} / \mathrm{C}_{\text {org }}$ ve $\mathrm{N}_{\text {mic }} / \mathrm{N}_{\text {total }}$ oranları orman alanında diğer arazi kullanımlarına göre daha düşük bulunmuştur. Bu durum orman topraklarının mikrobiyal biyokütle içeriğinin azlığından ziyade organik karbon ve toplam azot içeriklerinin yüksekliğinden ileri gelmektedir.

\section{Teşekkür}

$\mathrm{Bu}$ çalışma, birinci yazar tarafından hazırlanan yüksek lisans tezinden üretilmiştir. Bu vesile ile bu çalışmanın gerçekleştirilmesinde emeği geçen herkese, çalışmam boyunca benden bir an olsun yardımlarını esirgemeyen ve beni cesaretlendiren eşim Tûba BOLAT'a ve bu günlere gelmemde her türlü maddi ve manevi desteklerini 
esirgemeyen ve her zaman yanımda hissettiğim aileme sonsuz teşekkürlerimi sunarım.

\section{Kaynaklar}

1. Altunışık, R., Çoşkun, R. Yıldırım, E., Bayraktaroğlu, S. (2002). Sosyal Bilimlerde Araştırma Yöntemleri SPSS Uygulamalı, Geliştirilmiş 2. Basım, Sakarya Kitapevi, Sakarya Üniversitesi, İ.İ.B.F., Sakarya, 281 sayfa.

2. Anderson, J. P. E., Domsch, K. H. (1973). Quantification of bacterial and fungal contribution to soil respiration. Archives of Microbiology, 93, 113-127.

3. Anderson, J. M., Ingram, J. S. I. (1996). Tropical Soil Biology and Fertility A Handbook of Methods, Second Edition, Cab International Wallingford, UK, 221 pages.

4. Anderson, J. P. E., Domsch, K. H. (1989). Ratios of microbial biomass carbon to total organic carbon in arable soils. Soil Biology and Biochemistry, 21, 471-479.

5. Anderson, T. H., Domsch, K. H. (1986). Carbon assimilation and microbial activity in soil. Zeitschrift für Pflanzenernährung und Bodenkunde, 149, 457-468.

6. Bauhus, J. D., Pare, D., Cote, L. (1998). Effects of tree species, stand age, and soil type on soil microbial biomass and its activity in a southern boreal forest. Soil Biology and Biochemistry, 30, 1077-1089.

7. Brookes, P. C., Landman, A., Pruden, G., Jenkinson, D. S. (1985). Chloroform fumigation and the release of soil nitrogen: A rapid extraction metod to measure microbial biomass nitrogen in soil. Soil Biology and Biochemistry, 17, 837-842.

8. Carter, M. R., Gregorich, E. G., Angers, D. A., Beare, M. H., Sparling, G. P., Wardle, D. A., Voroney, R. P. (1999). Interpretation of microbial biomass measurements for soil quality assessment in humid temperate regions. Canadian Journal of Soil Science, 79, 507-520.

9. Christensen, M. (1989). A View of Fungal Ecology. Mycologia, 81(1), 1-19.

10. Cleveland C. C., Townsend A. R., Constance, B. C., Ley, R. E., Steven, K. S., (2004). Soil microbial dynamics in Costa Rica: seasonal and biogeochemical constraints. Biotropica, 36(2), 184-195.

11. Franzluebbers, A. J., Haney, R. L, Hons, F. M., Zuberer, D. A. (1999). Assessing biological soil quality with chloroform fumigation-incubation: Why subtract a control?. Canadian Journal of Soil Science, 79, 521-528.

12. García-Oliva, F., Lancho, J. F. G., Montaño, N. M., Islas, P. (2006). Soil carbon and nitrogen dynamics followed by a forest-to-pasture conversion in western Mexico. Agroforestry Systems, 66, 93-100.

13. Gülçur, F. (1974). Topră̆ın Fiziksel ve Kimyasal Analiz Metodları, Kutulmuş Matbaası, İ.Ü. Yayın No. 1970, Orman Fakültesi Yayın No. 201, İstanbul, 225 s.

14. Harita Genel Komutanlığı (HGT) (1984). 1:25 000 Ölçekli Zonguldak E28-c1, E28-c2, E28-c3, E28-c4 Topografik Haritaları, Ankara.

15. Hu, S., Coleman, D. C., Carroll, C. R., Hendrix, P. P., Beare, M. H. (1997). Labile soil carbon pools in subtropical forest and agricultural ecosystems as influenced by management practices and vegetation types. Agriculture, Ecosystems and Environment, 65, 69-78.

16. Irmak, A. (1954). Arazide ve Laboratuvarda Toprağın Araştırılması Metodları, İ.Ü. Yayın No. 559, Orman Fakültesi Yayın No. 27, İstanbul, 150 sayfa.

17. Jenkinson, D.S., Ladd, J. N. (1981). Microbial Biomass in Soil Measurement and Turnover. In Soil Biochemistry, Eds. Paul E.A. and Ladd J.N., Volume 5, Marcel Dekker, Inc, New York and Basel, pp. 415471.

18. Jenkinson, D. S. (1988). The determination of microbial biomass carbon and nitrogen in soil. In Advances in Nitrogen Cycling in Agricultural Ecosystems Ed. Wilson J.R., CAB, Wallingford, England, pp. 368-386.

19. Joergensen, R. G., Anderson, T. H., Wolters, V. (1995). Carbon and nitrogen relationships in the microbial biomass of soils in beech (Fagus sylvatica L.) forests. Biology and Fertility of Soils, 19, 141147.

20. Jörgensen, R. G. (1995). Die quantitative Bestimmung der mikrobiellen Biomasse in Böden mit der Chloroform-Fumigations-Extraktions-Methode. In Göttinger Bodenkundliche Berichte Ed. Meyer B., Selbstverlag Institut für Bodenwissenschaft Universität Göttingen, Vol. 104, pp. 1-229.

21. Kacar, B. (1996). Bitki ve Topră̆ın Kimyasal Analizleri, III. Toprak Analizleri. Ankara Üniv. Ziraat Fak. Eğitim, Araştırma ve Geliştirme Vakfı Yayınları No: 3, Ankara, 705 sayfa. 
22. Kaiser, E. A., Mueller, T., Joergensen, R. G., Insam, H., Heinemeyer, O. (1992). Evaluations of methods to estimate the soil microbial biomass and the relationship with the soil texture and organic matter. Soil Biology and Biochemistry, 24, 675-683.

23. Kara, Ö., Bolat, İ. (2008a). The effect of different land uses on soil microbial biomass carbon and nitrogen in Bartın province. Turkish Journal of Agriculture and Forestry, 32(4), 281-288.

24. Kara, Ö., Bolat, İ. (2008b). Microbial biomass $\mathrm{C}\left(\mathrm{C}_{\mathrm{mic}}\right)$ and $\mathrm{N}\left(\mathrm{N}_{\mathrm{mic}}\right)$ content of forest and agricultural soils in Bartın province, Turkey. Ecology, 18(69), 32-40.

25. Khan, K. S., Joergensen, R. G. (2006). Microbial C, N and P relationships in moisture stressed soils of Potohar, Pakistan. Journal of Plant Nutrition and Soil Science, 169, 494-500.

26. Luizao, R. C. C., Bonde, T. A., Rosswall, T. (1992). Seasonal variation of microbial biomass the effect of clear felling in a tropical rainforest and establishment of pasture of clearfelling in a tropical rain forest and establishment of pasture in the Central Amazon. Soil Biology and Biochemistry, 24, 805-813.

27. Nielsen, M. N., Winding, A. (2002). Microorganisms as Indicators of Soil Health. National Environmental Research Institute, Denmark. Technical Report No. 388, 84 pages.

28. Özdamar, K. (1999). Paket Programları ile İstatistiksel Veri Analizi SPSS MINITAP, İkinci Bask1, Kaan Kitapevi, Eskişehir, 689 sayfa.

29. Parkinson, D., Coleman, D. C. (1991). Microbial communities, activity and biomass. Agriculture, Ecosystems and Environment, 34, 3-33.

30. Priha, O., Smolander, A. (1997). Microbial biomass and activity in soil and litter under Pinus sylvestris, Picea abies and Betula pendula at originally similar field afforestation sites. Biology and Fertility of Soils, 24, 45-51.

31. Tate, K. R., Ross, D. J., Feltham, C. W. (1988). A direct extraction method to estimate soil microbial C: effects of experimental variables and some different calibration procedures. Soil Biology and Biochemistry, 20, 329-335.

32. Thornthwaite C. W. (1948). An approach toward a rational classification of climate. Geographical Review, 38, 55-94.

33. Vance, E. D., Brookes, P.C., Jenkinson, D. S. (1987a). An extraction method for measuring soil microbial biomass C. Soil Biology and Biochemistry, 19, 703-707.

34. Vance, E. D., Brookes, P. C., Jenkinson, D. S. (1987b). Microbial biomass measurements in forest soils: The use of the chloroform fumigation incubation method for strongly acid soils. Soil Biology and Biochemistry, 19, 697-702.

35. Yeates, G. W., Saggar, S. (1998). Comparison of soil microbial properties and fauna under tussockgrassland and pine plantation. Journal of The Royal Society of New Zealand, 28(3), 523-535.

36. Yuan, B. C., Li, Z. Z., Liu, H., Gao, M., Zhang, Y. Y. (2007). Microbial biomass and activity in salt affected soils under arid conditions. Applied Soil Ecology, 35, 319-328.

37. Zhong, Z., Makeschin, F. (2006). Differences of soil microbial biomass and nitrogen transformation under two forest types in central Germany. Plant and Soil, 283, 287-297. 